\title{
Impact of dew deposition on water flux dynamics at a tropical rainfed paddy field in the dry season
}

\author{
Daisuke KOMORI ${ }^{\mathrm{a}, \dagger}$ and Wonsik KIM ${ }^{\mathrm{b}}$ \\ ${ }^{\text {a }}$ Graduate school of Environmental Studies, Tohoku University, Sendai, Miyagi, 980-8579, Japan \\ ${ }^{\mathrm{b}}$ National Institute for Agro-Environmental Sciences, Tsukuba, Ibaraki, 305-8604, Japan
}

\begin{abstract}
Dew deposition and its impact on water flux dynamics at a rainfed paddy field in northern Thailand during the dry season were investigated. Daytime evaporation was found to be related to the soil water content after the paddy had been drained and to the nighttime water addition after the paddy soil surface strongly dried. Consequently, daytime evaporation decreased because of nighttime dew deposition ceased due to increased soil surface temperature. Thus, daytime evaporation from rainfed paddy fields appears to be controlled by the timing of paddy water discharge and dew deposition. This finding differs from earlier studies in arid and semiarid regions that showed that the dew deposition on a bare soil surface is probably rare because the dew-point temperature is lower than the soil surface temperature due to the lack of water vapor content (WVC) in the atmosphere. This result indicates that atmospheric WVC might play a key role in water addition to the soil and water flux dynamics in the tropics.
\end{abstract}

Key words: Dew deposition, Dry season, Evaporation, Rainfed rice paddy, Tropics.

\section{Introduction}

Human activities, such as the conversion of natural vegetation to cropland, could have a critical effect on regional hydrological cycles and climate (Henderson-Sellers et al., 1993; Zheng and Eltahir, 1998). The potential impact of rice cultivation on regional climate in the tropics has been a controversial issue because rice cultivation occupies a significant fraction of land soil surface converted from natural vegetation and forests over the last century. Previous studies have suggested that changes in evapotranspiration (ET) as a result of deforestation have decreased regional precipitation in Thailand (Kanae et al., 2001) and that the increase of ET due to land use/cover changes has decreased the runoff in the Chao Phraya river watershed, Thailand (Kim et al., 2005). Furthermore, ET measurement over a diverse land use area in northern Thailand verified that the interannual variation in ET reflected the response of the land soil surface to meteorological events (Kim et al., 2014). These studies indicate that ET reflected response of land use played a significant role in the hydrological cycle in Thailand.

Rainfed rice paddies are a typical and traditional form of rice cultivation in the tropics, accounting for $77 \%$ of the total area under rice cultivation in Thailand, and approximately 55\% in the tropics (Mutert and Fairhurst, 2002; Redfern et al., 2012). Many studies have investigated rice production in terms of agricultural productivity and water availability at irrigated and rainfed rice paddies during the rice cultivation season (Fukai et al., 1998; Wade et al., 1999; Lee et al., 2004; Attarod et al., 2005, 2006; Tsubo et al., 2007). During the non-rice season, i.e., the dry season, ET at rainfed paddy fields is considered to be almost zero

Received; August 11, 2014.

Accepted; October 29, 2015.

${ }^{\dagger}$ Corresponding Author: daisuke.komori.e8@tohoku.ac.jp

DOI: 10.2480/agrmet.D-14-00036 because the soil surface is completely dry. However, Grunberger et al. (2008) found that average evaporation flux at a loamy rainfed paddy in northeast Thailand during February ranged between $0.2-0.3 \mathrm{~mm} \mathrm{day}^{-1}$. Furthermore, Kim et al. (2014) indicated that the large interannual variation in ET during the dry season was caused by heterogeneous land surface moisture content. However, how water is evaporated at a fully dried tropical rainfed paddy field in the dry season is not clearly understood. Since rainfed paddy fields occupy a large portion of land surface in the tropics and have a high impact on regional climate, it is important to understand the water flux dynamics of tropical rainfed paddy fields in the dry season.

Previous studies that measured ET over various types of vegetation in arid and semiarid regions have reported that daytime ET was caused by the water added to bare soil surfaces in arid environments on numerous nights (Kosmas et al., 1998; Kidron, 2000). Katata et al. (2007) examined the evaporation and adsorption processes in soil using a one-dimensional soil model. The water added by either dew deposition or direct water vapor adsorption evaporated the following day, thereby changing the pattern of radiant energy dissipation, i.e., sensible heat $(\mathrm{H})$ was converted to latent heat (IE). Therefore, the understanding of water flux dynamics at rainfed paddy fields in the dry season is important to clarify both water exchange and energy exchange between the air and soil surface.

The goals of this study are to quantify and characterize water flux dynamics at tropical rainfed rice paddy fields in the dry season. In addition, this study also sought to identify the mechanisms of water addition, soil evaporation, dew deposition, and water vapor adsorption. We investigated the monthly and daily changes in daytime evaporation and meteorological variables, and observed the nighttime water dynamics at a rainfed paddy field during the dry season in Thailand. 


\section{Materials and Methods}

\subsection{Study site}

The study site was a typical rainfed paddy field located at a flood plain in the Chao Praya river watershed, Thailand $\left(17^{\circ} 04^{\prime} \mathrm{N}\right.$, $99^{\circ} 42^{\prime} \mathrm{E}$; $194 \mathrm{~m}$ above mean sea level). The climate is a tropical savanna climate. The soil at the study site is a sandy loam. The dry bulk density is 1.76, and the Food and Agriculture Organization (FAO) soil classification is acrisol. Typically in these regions, rice was seeded in July under submerged conditions and harvested during late November and December.

Table 1 shows climatological data for the period 1971-2000, recorded by the meteorological station nearest to the study site (Phitsanulok station; $16^{\circ} 47^{\prime} \mathrm{N}, 100^{\circ} 16^{\prime} \mathrm{E} ; 45 \mathrm{~m}$ above mean sea level). Average annual precipitation and air temperature for 1971-2000 were $1337 \mathrm{~mm}$ and $27.7^{\circ} \mathrm{C}$, respectively. Nearly $90 \%$ of the precipitation fell in the wet season between May and October; average monthly precipitation exceeded $100 \mathrm{~mm}$. Only $4 \%$ of the precipitation fell in the dry season from November to February. In this period, the monthly mean minimum temperature was $2{ }^{\circ} \mathrm{C}$ lower than the annual average. The remaining approximately $6 \%$ of the precipitation fell in the dry period during March and April, when the monthly mean maximum temperature was $2^{\circ} \mathrm{C}$ higher than the annual average. Hence, the dry season can be divided into a cool dry season and a hot dry season. The monthly mean relative humidity $(\mathrm{RH})$ in the wet, cool dry, and hot dry seasons were $77 \%, 67 \%$, and $61 \%$, respectively, reflecting the variation in precipitation. The monthly mean maximum $\mathrm{RH}$ in all seasons was higher than $80 \%$.

\subsection{Field data}

A $10-\mathrm{m}$ tower at the study site was used for micrometeorological measurements from October 2006 until March 2007. The net radiation $(\mathrm{Rn})$ at the soil surface was measured by short- and long-wave radiometers (CNR1, Kipp \& Zonen, Inc.) mounted on the tower at a height of $2 \mathrm{~m}$. The temperature and RH were measured by ventilated thermo-hygrometers (HMP45A, Vaisala, Inc.) mounted at 2 and $10 \mathrm{~m}$ on the tower, respectively. The atmospheric pressure was measured by a barometric pressure sensor mounted at $1 \mathrm{~m}$ (61202, R.M. Young, Co). The specific humidity (qh) was calculated from the temperature, $\mathrm{RH}$, and atmospheric pressure measurements. An infrared thermometer, (P-IRT/C-1XT50F,
Ogasawara Keiki Sesakusho Co., Ltd.) which is used to measure soil surface temperature, was also installed at $10 \mathrm{~m}$ on the tower. Soil moisture sensors (CS615, Campbell Scientific, Inc.) and temperature sensors (copper-constantan thermocouple, handmade) were installed at depths of $0.05,0.10,0.15$, and $0.20 \mathrm{~m}$ in the soil. The soil water potential $(\mathrm{pF})$ profiles and soil heat flux (G) were calculated from these soil measurements. Rainfall was measured with a rain gauge (34-T, OTA Keiki Seihakusho, Co., Ltd.). All data were logged every minute, averaged over $10 \mathrm{~min}$, and recorded with a data logger (CR10X, Campbell Scientific).

In addition, 60-min $\mathrm{H}$ and $\mathrm{ET}$ were measured by the eddy covariance (EC) method using a three-dimensional sonic anemometer (CSAT3, Campbell Scientific) and an open-path $\mathrm{CO}_{2} / \mathrm{H}_{2} \mathrm{O}$ gas analyzer (LI7500, LI-COR, Inc.) at a sampling rate of $10 \mathrm{~Hz}$. These instruments were attached to the tower at a height of $7 \mathrm{~m}$. Data were recorded with a data logger (CR5000, Campbell Scientific). Atmospheric stability was computed from the EC measurement. To assess the quality control and assurance (QC/QA) of EC data, a fractional uncertainty $(T)$ proposed by Kim et al. (2009) was applied because it provides quantitative information about the uncertainty of EC measurement (Kim et al., 2011). The flux $(F)$ is computed using the EC method as follows:

$$
F=\operatorname{Cov}\{x, y\}=\frac{1}{n} \sum_{t=1}^{n}\left(x_{t}-\bar{x}\right)\left(y_{t}-\bar{y}\right) .
$$

Here, ${ }^{-}$represents the average; $x$ is a vertical wind velocity; and $y$ is a scalar quantity, e.g., a scalar of the temperature or mixing ratio of the vapor or trace gas; and $n$ denotes the number of samples in an averaging interval time (i.e., $n=36000$ in this study). Here, $\mathrm{T}$ of EC is defined as follows:

$$
T=\frac{\sqrt{\operatorname{Var}\left\{\gamma_{x y}\right\}}}{|\operatorname{Cov}\{x, y\}|} \text {. }
$$

The variance in the numerator is expressed as follows:

$$
\operatorname{Var}\left\{\gamma_{x y}\right\}=\frac{1}{n}\left[\sum_{h=-m}^{m} \gamma_{x x}(h) \gamma_{y y}(h)+\sum_{h=-m}^{m} \gamma_{x y}(h) \gamma_{y x}(h)\right]
$$

(Meyers et al., 1998; Finkelstein and Sims, 2001), and the covariance in the denominator is expressed by Equation (1). Here, $m$ is

\begin{tabular}{|c|c|c|c|c|c|c|c|c|c|c|c|c|c|}
\hline & JAN & FEB & MAR & APR & MAY & JUN & JUL & AUG & SEP & OCT & NOV & DEC & ANNUAL \\
\hline \multicolumn{14}{|c|}{ Temperature(Celsius) } \\
\hline Mean & 24.5 & 26.7 & 29.1 & 30.7 & 29.8 & 28.9 & 28.4 & 28.0 & 28.1 & 27.7 & 26.1 & 24.1 & 27.7 \\
\hline Mean max. & 31.7 & 33.9 & 35.9 & 37.3 & 35.7 & 33.9 & 33.1 & 32.4 & 32.5 & 32.3 & 31.5 & 30.7 & 33.4 \\
\hline Mean min. & 18.4 & 20.8 & 23.7 & 25.5 & 25.3 & 25.0 & 24.8 & 24.6 & 24.7 & 24.1 & 21.6 & 18.4 & 23.1 \\
\hline \multicolumn{14}{|c|}{ Relative Humidity (\%) } \\
\hline Mean & 65 & 62 & 61 & 62 & 71 & 76 & 78 & 80 & 80 & 78 & 72 & 67 & 71 \\
\hline Mean max. & 85 & 81 & 80 & 80 & 86 & 89 & 90 & 92 & 92 & 91 & 88 & 86 & 87 \\
\hline $\begin{array}{l}\text { Mean min. } \\
\text { Rainfall (m }\end{array}$ & 39 & 38 & 39 & 41 & 51 & 58 & 61 & 64 & 64 & 60 & 51 & 42 & 51 \\
\hline Mean & 5 & 13 & 31 & 55 & 178 & 180 & 188 & 257 & 231 & 159 & 33 & 7 & 1337 \\
\hline
\end{tabular}
the number of samples that are sufficiently large to capture an

Table 1. Climatological data for the period 1971-2000 observed by the Phitsanulok meteorological station. 
integral timescale (i.e., $m=200$ because the estimated $T$ is unaffected by $m>200$ throughout the testing of our data sets). Equation (2) is estimated by the auto-covariance of the lag time $h$ :

$$
\gamma_{x x}(h)=\gamma_{x x}(-h)=\frac{1}{n} \sum_{t=1}^{n-h}\left(x_{t}-\bar{x}\right)\left(x_{t+h}-\bar{x}\right)
$$

and the cross-covariance of $h$

$$
\gamma_{x y}(h)=\gamma_{y x}(-h)=\frac{1}{n} \sum_{t=1}^{n-h}\left(x_{t}-\bar{x}\right)\left(y_{t+h}-\bar{y}\right)
$$

with each sample time series. The period $\mathrm{F}$ and $\mathrm{T}$ are integrated using a weighted mean method (Kim et al., 2015). The corrections to ET are conducted as described by Webb et al., (1980) and Leuning (2004) after $\mathrm{T}$ is estimated. In the calculation process, the turbulence trends, including consecutive spikes, were discarded according to Vickers and Mahrt (1997). Since the nighttime EC data demonstrates large $T$ and accurate methods of measurements for water addition to the soil surface have not been developed yet, we observed the nighttime potential dew deposition using the surrogate surface method (Kidron, 2000; Beysens et al., 2005) at the study site to understand the relationship between nighttime dew deposition and daytime evaporation. Note that "daytime" is defined as the period during the positive $\mathrm{Rn}$, and "nighttime" is defined as negative Rn. To recreate natural soil surface conditions after the rice harvest, we constructed six surrogate surfaces using dry straw on $2.2 \times 1.8 \mathrm{~m}^{2}$ cotton blankets. The thermal conductivity of the cotton blanket was $0.03 \mathrm{~W} \mathrm{~m}^{-1} \mathrm{~K}^{-1}$ (http://www.hitek-ltd.co.uk/media/downloads/603/Thermal\%20 conductivity $\% 20$ of $\% 20$ Common $\% 20$ Materials.pdf), which was similar to that of air $\left(0.0241 \mathrm{~W} \mathrm{~m}^{-1} \mathrm{~K}^{-1}\right)$. The surrogate surfaces were positioned to avoid direct contact with the soil surface. We calculated potential dew deposition from the weight differences between the dry surrogate surfaces, which were put in place after sunset, and the surrogate surfaces that were wetted during the night. Potential dew deposition was observed continuously from January 14 to February 4, 2007.

\section{Results and Discussion}

\subsection{Characteristics of daytime evaporation after rice harvest- ing}

Figure 1 shows the transition in 10 day-averaged daytime total ET and meteorological variables during the dry season from October 21, 2006 to March 31, 2007 at the study site. Paddies at the study site were drained for the harvest on October 19, and rice was harvested on November 7 . The temperature drastically decreased in December 2006, followed by increases in February 2007. Therefore, for 2006-2007, it was considered that the cool dry season began during the middle 10 days of December 2006 and the hot dry season began during the middle 10 days of February 2007 . Average temperature during the cool and hot dry seasons was $22.9^{\circ} \mathrm{C}$ and $29.3^{\circ} \mathrm{C}$, respectively. qh at $2 \mathrm{~m}$ also decreased rapidly from 20 to $16 \mathrm{~g} \mathrm{~kg}^{-1}$ after the paddy was drained and decreased continuously to $9 \mathrm{~g} \mathrm{~kg}^{-1}$ in the cool dry season. During the cool and hot dry seasons, the average qh at $2 \mathrm{~m}$ was 11 and $13 \mathrm{~g} \mathrm{~kg}^{-1}$, respectively. The qh at $2 \mathrm{~m}$ in the dry season was approximately $60 \%$ of that in the wet season. The soil water content (SWC) at $0.05-\mathrm{m}$ depth in the soil drastically decreased from $32 \%$ to $14 \%$ during the month following paddy drainage and continuously decreased during the dry season. Average SWC at $5-\mathrm{cm}$ depth was $6 \%$ during the cool dry season and 5\% during the hot dry season. SWC at $20-\mathrm{cm}$ depth also decreased from $37 \%$ to $23 \%$ during the month following paddy drainage; however, average SWC was $18 \%$ during the cool dry season and $17 \%$ during the hot dry season. Daytime ET also drastically decreased with the de-

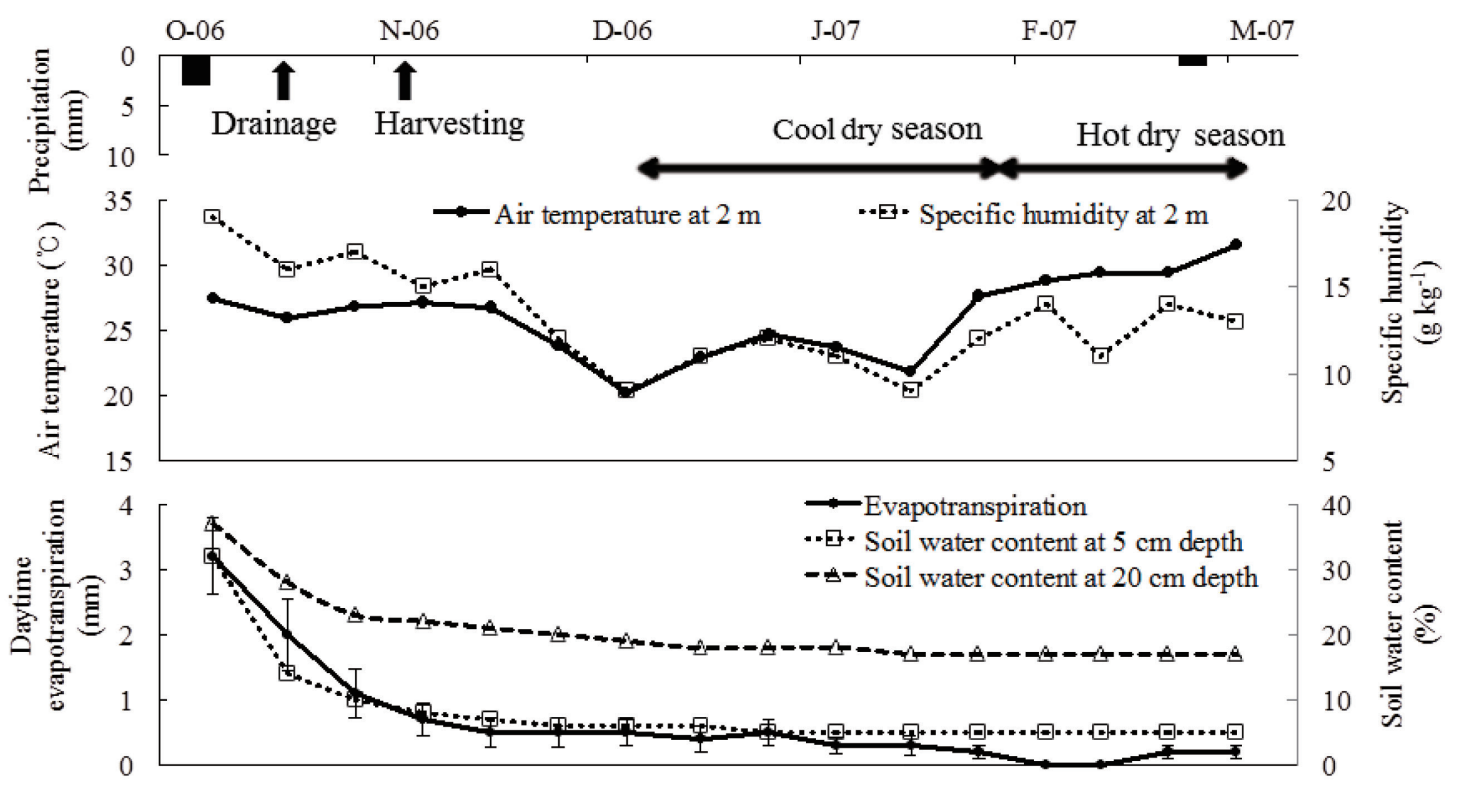

Fig. 1. Transition in 10 day-averaged daytime total evapotranspiration and daily meteorological variables during the dry season from October 21, 2006 to March 31, 2007 at the study site. Paddies at the study site were drained for the harvest on October 19, and rice was harvested on November 7. Error bar of evapotranspiration denotes $T$. 
crease of SWC at 5-cm depth. Daytime ET was 0.2-0.3 mm during the cool dry season; however, daytime ET was zero during the hot dry season until the first rain (March 20, 2007). Total daytime ET from the last rain in 2006 (October 29, 2006) to the first rain in 2007 was approximately $70 \mathrm{~mm}$. This ET indicates evaporation after rice harvesting in December.

To elucidate the characteristics of daytime evaporation at the study site, we compared evaporation averaged from October 2130, 2006 (OCT), November 11-20, 2006 (NOV), December 1120, 2006 (DEC), January 1-10, 2007 (JAN), February 1-10, 2007 (FEB), and March 1-10, 2007 (MAR) (Fig.2). Daytime evaporation in OCT shifted following the variation of Rn. The water retention capacity of the soil was equal to that just after discharging the water in the submerged paddy; this indicates that the daytime evaporation was affected by Rn. In NOV, the daytime evaporation peak occurred at 09:00 local standard time (LST), and the amount of evaporation was similar to that at 09:00 LST in OCT. However, daytime evaporation did not increase with Rn. The total daytime evaporation was $1.21 \mathrm{~mm}$, which was only $30 \%$ of that in OCT. Since SWC in NOV was much lower than that in OCT (Fig.1), the daytime evaporation was strongly controlled by low SWC. In the cool dry season, daytime evaporation until 09:00 LST in DEC was half of the value at the same time in NOV, and daytime evaporation after 10:00 LST was remarkably lower than that in NOV. Daytime evaporation in JAN and FEB showed the similar daily cycles of daytime evaporation in DEC. Evaporation from 08:00 LST to 10:00 LST in JAN and FEB were 0.19 and $0.15 \mathrm{~mm}$, respectively, and accounted for approximately half of the total evaporation. In the hot dry season, the total daytime evaporation in MAR was almost zero.

Figure 3 shows the transition of $\mathrm{pF}$ profiles at 00:00 LST, 06:00
LST, 12:00 LST, and 18:00 LST for the same period given in Fig.2. The $\mathrm{pF}$ profiles in OCT ranged between gravitational water $(0<\mathrm{pF}<1.8)$ and capillary water $(1.8<\mathrm{pF}<4.2)$. Gravitational water occupies larger soil pores and moves down readily under the force of gravity, while capillary water is held in the capillary pores by soil surface forces and evaporates easily at normal temperatures. Similarly, the $\mathrm{pF}$ profiles in NOV were within the range of capillary water. Therefore, in OCT and NOV, the soil internal evaporation reflected the soil surface evaporation. In other periods, the $\mathrm{pF}$ profiles ranged between capillary and adsorptive waters $(4.2<\mathrm{pF}<7.0)$. As adsorptive water is held tenaciously by soil surface forces, adsorptive water cannot be separated from the soil unless it is heated. Therefore, the contribution of the soil internal evaporation to the soil surface evaporation could be considered small in DEC, JAN, FEB, and MAR.

\subsection{Nighttime water addition to the soil surface during the dry season}

Agam and Berliner (2006) defined dew deposition that occurs when the soil surface temperature is lower than or equal to the dew-point temperature, and defined water vapor adsorption that occurs when the soil surface temperature is higher than the dew-point temperature and the RH of the soil pores is lower than that of the air.

To identify whether water was added to the soil by dew deposition or direct water vapor adsorption in the nighttime during the dry season, the transitions of soil surface temperature, dew-point temperature at $2 \mathrm{~m}$, and the ratio of specific humidity at $2 \mathrm{~m}$ and saturated specific humidity at soil surface $\left(\mathrm{qh} / \mathrm{qh}_{\mathrm{SAT}}\right)$ are shown in Fig.4 for the same period as in Fig. 2. Since SWC at the soil surface was not observed, we assumed that the $\mathrm{qh}^{\mathrm{q} h} \mathrm{SAT}_{\mathrm{SAT}}$ greater than 1.0, i.e., the atmospheric saturated condition immediately above the soil surface, indicating that water was added to the soil by dew deposition. In OCT, NOV, and DEC, the nighttime soil

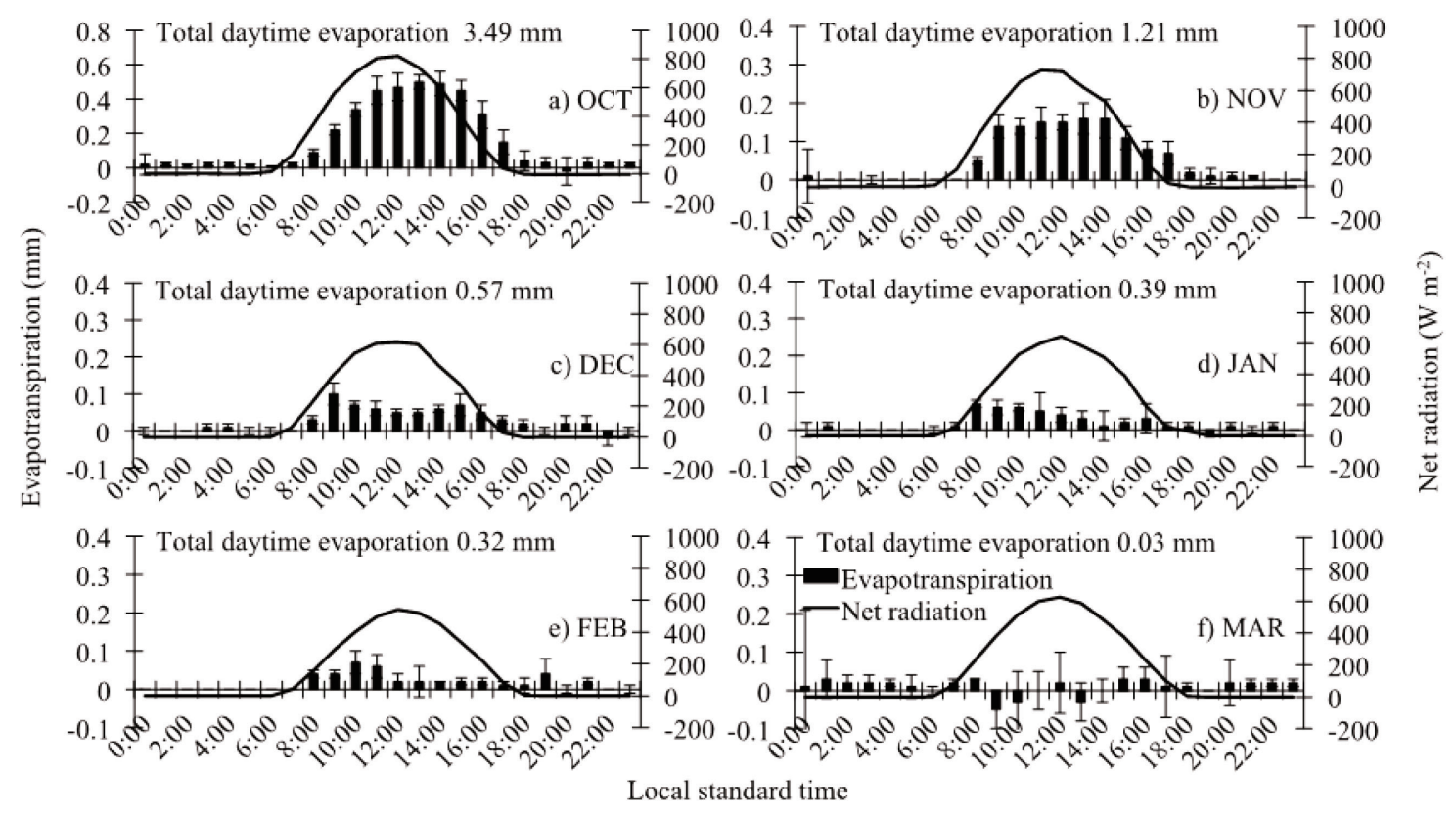

Fig. 2. Temporal changes in the 10-day average daytime evaporation and net radiation at the study site from a) October 21-30, 2006, b) November 11-20, 2006, c) December 11-20, 2006, d) January 1-10, 2007, e) February 1-10, 2007, and f) March 1-10, 2007. Error bar of evapotranspiration denotes $T$. 


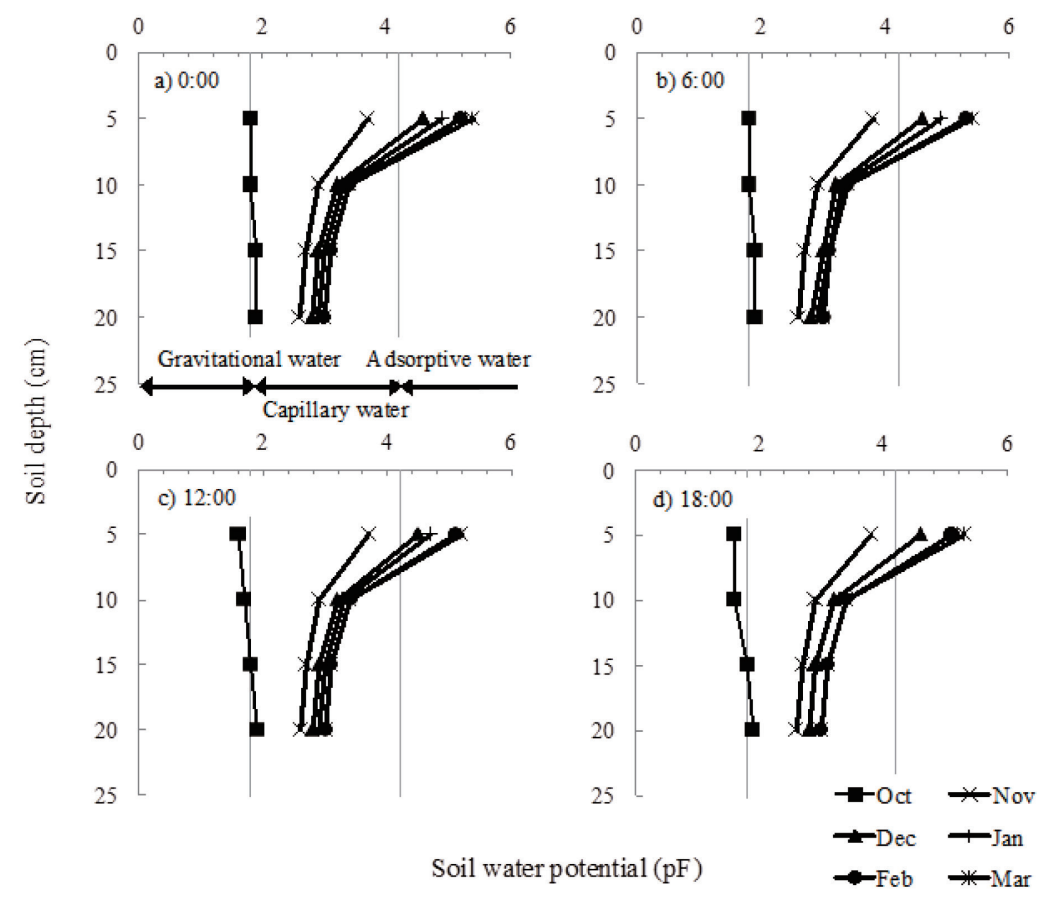

Fig. 3. Transition of soil water potential $(\mathrm{pF})$ profiles at 00:00, 06:00, 12:00, 18:00 (Local standard time) for the same period given in Fig. 2.

surface temperatures were clearly lower than the dew-point temperature at $2 \mathrm{~m}$. The nighttime $\mathrm{qh} / \mathrm{qh}_{\mathrm{SAT}}$ was also greater than 1.0. These suggest that water was potentially transferred from the atmosphere to the soil surface by nighttime dew deposition in OCT, NOV, and DEC. On the other hand, the nighttime soil surface temperature in JAN and FEB was not lower than the dew-point temperature at $2 \mathrm{~m}$ until midnight and that in MAR was not lower than the dew-point temperature at $2 \mathrm{~m}$ throughout the night. The nighttime $\mathrm{qh} / \mathrm{qh}_{\mathrm{SAT}}$ in JAN, FEB, and MAR was not greater than 1.0 when the nighttime soil surface temperature was not lower than the dew-point temperature. These also suggest that water was added to the soil by dew deposition from midnight to early morning in JAN and FEB and was not added by dew deposition in MAR.

Although the nighttime soil surface temperature was not lower than the dew-point temperature at $2 \mathrm{~m}$, water was potentially transferred from the atmosphere to the soil surface by direct water vapor adsorption when the nighttime qh was higher than that of soil surface. The nighttime $\mathrm{qh} / \mathrm{qh}_{\mathrm{SAT}}$ was greater than 0.8 from 20:00 LST in JAN and from 22:00 LST in FEB; however, it did not reach 0.8 in MAR. Considering that the morning evaporation in MAR was almost zero (Fig. 2), it was confirmed that direct water vapor adsorption could be considered small when the nighttime $\mathrm{qh} / \mathrm{qh}_{\mathrm{SAT}}$ was lower than 0.8 .

Therefore, we postulated that water was added to the soil by dew deposition and direct water vapor adsorption in the nighttime from the late wet season until the hot dry season and by direct water vapor adsorption in the nighttime during the hot dry season. Furthermore, the decrease of morning evaporation in FEB and MAR indicates that water addition to the soil was limited by the atmospheric unsaturated condition.

3.3 Impact of nighttime water addition on surface water balance

We observed nighttime potential dew deposition using the surrogate surface method at the study site from January 14 to Febru- ary 4, 2007 to estimate the total amount of nighttime water addition to the soil surface during the cool dry season. Fig. 5 shows the transition of nighttime potential dew deposition and morning evaporation from 08:00 LST to 10:00 LST which water was potentially added to the soil during the last night was evaporated, and the ratio of morning flux imbalance $\left(\left(\mathrm{R}_{n}-\mathrm{H}^{-}-\mathrm{E}-\mathrm{G}\right) / \mathrm{R}_{\mathrm{n}}\right)$. As shown in Fig. 2, morning evaporation accounted for approximately half of the daytime evaporation during this period. The morning evaporation and nighttime potential dew deposition ranged from -0.07 to $0.28 \mathrm{~mm}$ and from 0.05 to $0.21 \mathrm{~mm}$, respectively. Although some morning evaporation values were negative or lower than the nighttime potential dew deposition because evaporation was limited by both wet soil conditions due to dew deposition and weather conditions, such as radiation and wind, the nighttime potential dew deposition well matched the morning evaporation. Almost ratios of morning flux imbalance were smaller than 0.30 which was reported from previous studies (e.g. Panin et al., 1998), and these average was -0.03 . It was suggested that the errors from morning flux imbalance on morning evaporation was small.

The observed morning evaporation and nighttime potential dew deposition are plotted in Fig. 6. Almost all nighttime potential dew deposition accounted for more than $50 \%$ of the morning evaporation. The total nighttime potential dew deposition corresponded to approximately $87 \%$ of the total morning evaporation. Although plotted morning evaporation had large $T$ values and the observed dew deposition corresponded to the potential amount, it was suggested that the strong impact of nighttime water addition to the soil surface on morning evaporation was recognized at the rainfed paddy field during the cool dry season after the soil surface had become dry. 


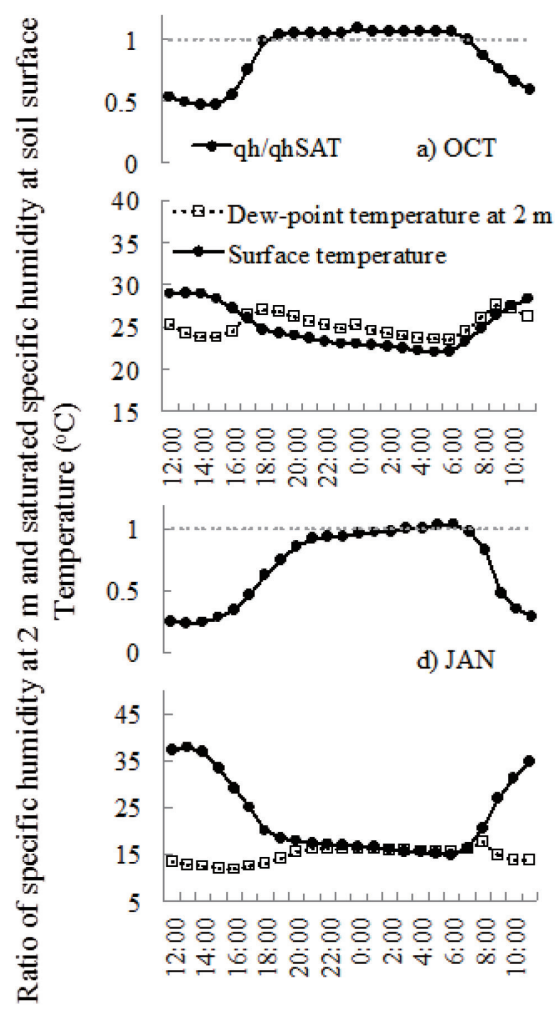

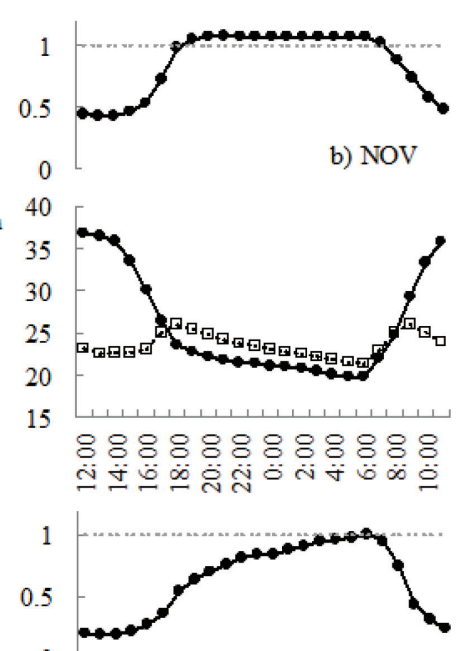

e) FEB

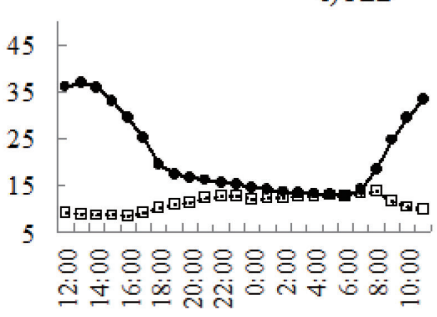

Local standard time

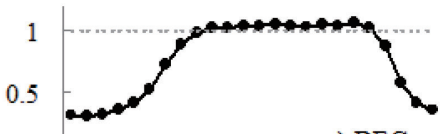

c) DEC

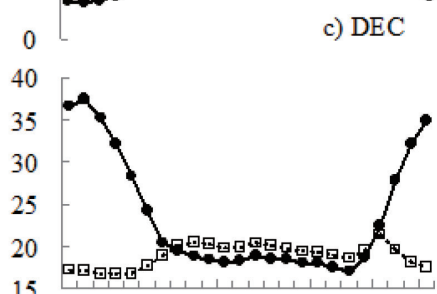

888888888888

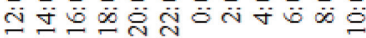

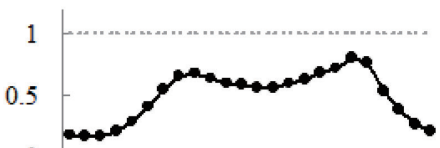

f) MAR

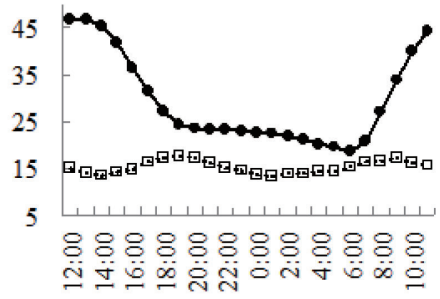

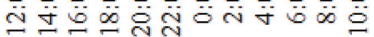

Fig. 4. Temporal changes in the 10-day average soil surface temperature, dew-point temperature at $2 \mathrm{~m}$, and ratio of specific humidity at $2 \mathrm{~m}$ and saturated specific humidity at soil surface $\left(\mathrm{qh} / \mathrm{qh}_{\mathrm{SAT}}\right)$ measured at the study site for the same period as shown in Fig. 2.
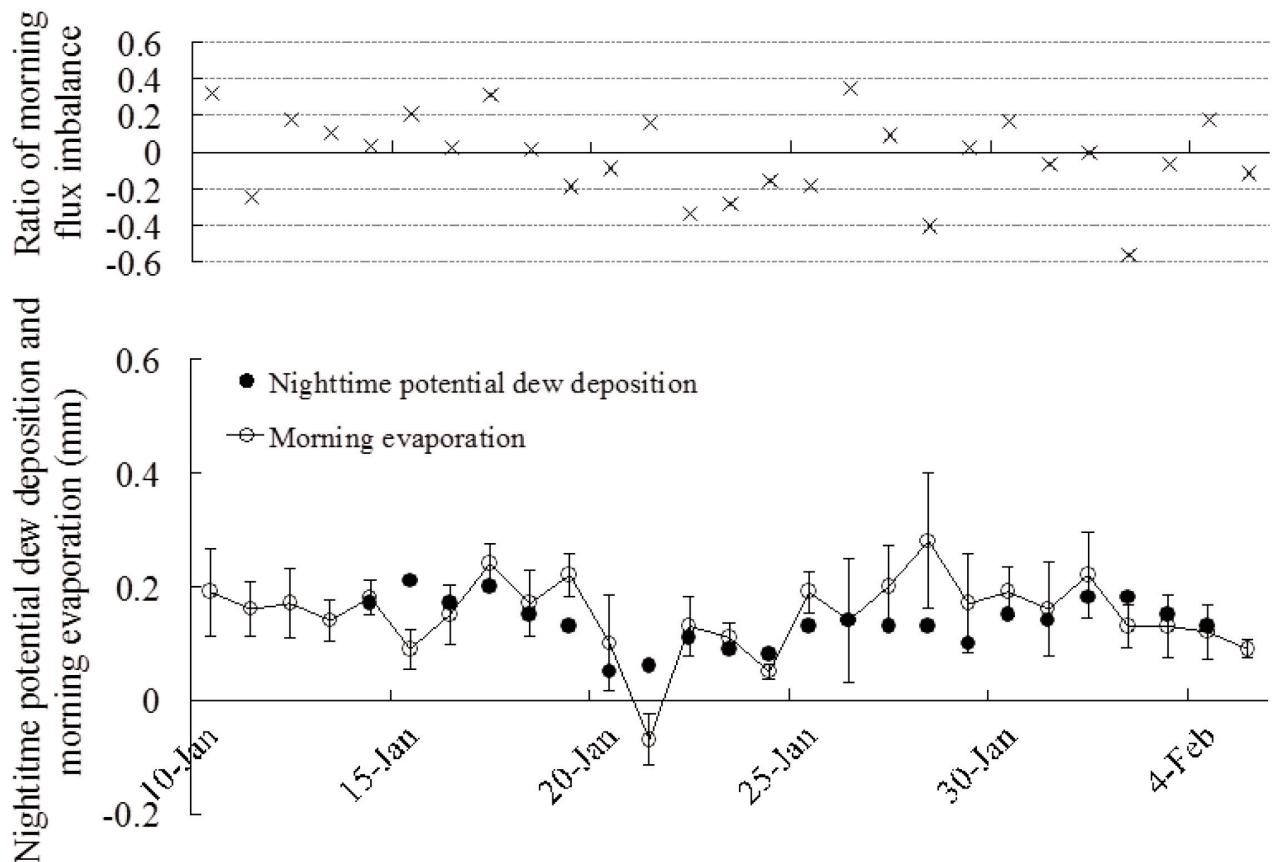

Fig. 5. Transition of 10-days averaged morning evaporation, nighttime potential dew deposition, and the ratio of morning flux imbalance $\left.\left(\mathrm{R}_{\mathrm{n}}-\mathrm{H}-\mathrm{lE}-\mathrm{G}\right) / \mathrm{R}_{\mathrm{n}}\right)$ at the study site. Error bar of morning evaporation denotes $\mathrm{T}$.

\section{Conclusion}

This study indicates that daytime evaporation from rainfed rice paddy fields after harvesting appears to be controlled by the tim- ing of paddy water discharge and nighttime water addition. Daytime evaporation was related to SWC after the water in a flooded paddy field had been discharged. Furthermore, the morning evaporation after the soil surface had dried indicates that water was 


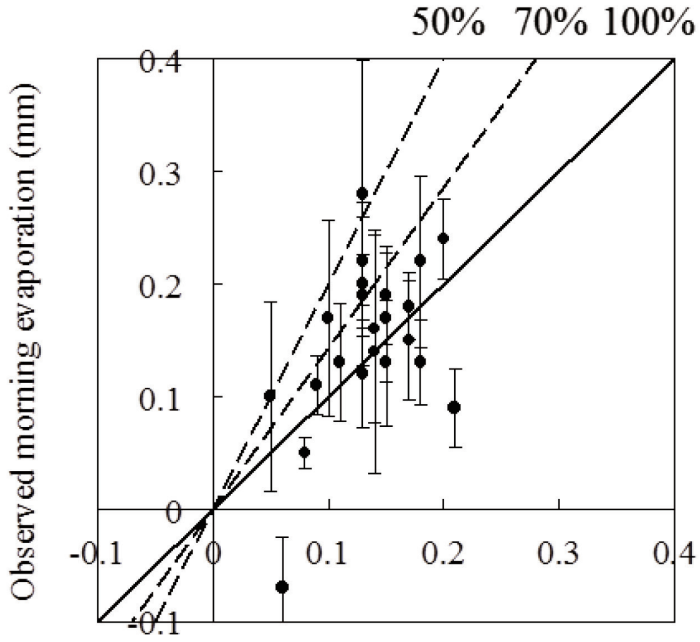

Nightime potential dew deposition ( $\mathrm{mm}$ )

Fig. 6. Comparison between the total amounts of morning evaporation and nighttime potential dew deposition. Solid and dashed lines indicate the ratio of nighttime potential dew deposition and morning evaporation. Error bar of morning evaporation denotes $\mathrm{T}$.

added to the soil during the night because the soil internal evaporation was negligible. Finally, daytime evaporation decreased due to decreased morning evaporation. We inferred that the morning evaporation decreased because of nighttime dew deposition ceased due to increased soil surface temperature. Thus, it was suggested that water was added to the soil primarily by nighttime dew deposition after harvesting in the cool dry season. In addition, because the nighttime potential dew deposition was smaller than the morning evaporation (Fig. 6), and the morning evaporation accounted for approximately half of the daytime evaporation during this period (Fig. 2), direct water vapor adsorption and soil internal evaporation are also thought to contribute to total daytime evaporation in the cool dry season.

Furthermore, previous studies of arid and semiarid regions showed that actual dew deposition on a bare soil surface is probably rare because the dew-point temperature is lower than the soil surface temperature due to the lack of water vapor content (WVC) in the atmosphere (Agam and Berliner, 2004). In contrast, this study showed that the dew-point temperature is higher than or equal to the soil surface temperature. WVC in the dry season was significant, i.e., approximately $60 \%$ of that in the wet season (October); thus, it contributed to the increase in dew-point temperature. This indicates that WVC in the atmosphere might play a key role in water addition to the soil and water flux dynamics at tropical rainfed paddy fields. Since rainfed paddy fields accounted for approximately $50 \%$ in major countries in tropics, WVC in the atmosphere is also considered to play a significant role in the hydrological cycle in the tropics.

\section{Acknowledgements}

This study was partially supported by the Science and Technology Research Partnership for Sustainable Development, Japan
Science and Technology Agency-Japan International Cooperation Agency, and the Ministry of Education, Science, Sports and Culture, Japan, Grant-in-Aid for Scientific Research (S), 23226012, 2011. The authors would like to express their sincere gratitude to Professor Masatoshi Aoki of the Tokyo University of Agriculture and Technology, Professor Taikan Oki of the University of Tokyo, Professor Shinjiro Kanae of the Tokyo Institute of Technology, and Dr. Jaeil Cho of Pukyong National University who provided a great deal of valuable advice. In Thailand, tremendous cooperation was provided by Mr. Nontawat Junjareon of Kasetsart University, and Mr. Panya Polson, Mr. Jaray Thongduang, and Mr. Wichai Chansing of the Royal Irrigation Department of the Ministry of Agriculture and Cooperatives. The authors offer their sincere appreciation for this cooperation.

\section{References}

Agam, N., and Berliner, P. R., 2004: Diurnal water content changes in the bare soil of a coastal desert. Journal of Hydrometeorology, 5, 922-933,

doi: 10.1175/1525-7541 (2004) 005<0922:DWCCIT>2.0.CO;2.

Agam, N., and Berliner, P. R., 2006: Dew formation and water vapor adsorption in semi-arid environments-A review. Journal of Arid Environments, 65, 572-590, doi: 10.1016/j.jaridenv.2005.09.004.

Attarod, P., Komori, D., Hayashi, K., Aoki, M., Ishida, T., Fukumura, K., Boonyawat, S., Polsan, P., Tongdeenok, P., Somboon, P., and Punkngum, S., 2005: Comparison of the evapotranspiration among a paddy field, cassava plantation, and teak plantation in Thailand. Journal of Agricultural Meteorology, 60, 789792.

Attarod, P., Aoki, M., Komori, D., Ishida, T., Fukumura, K., Boonyawat, S., Tongdeenok, P., Yokoya, M., Punkngum, S., and Pakoktom, T., 2006: Estimation of crop coefficients and evapotranspiration by meteorological parameters in a rain-fed paddy rice field, cassava, and teak plantations in Thailand. Journal of Agricultural Meteorology, 62, 93-102, doi: 10.2480/agrmet.62.93.

Beysens, D., Muselli, M., Nikolayev, V., Narhe, R., and Milimouk, I., 2005: Measurement and modelling of dew in island, coastal and alpine areas. Atmospheric Research, 73, 1-22, doi: 10.1016/j.atmosres.2004.05.003.

Finkelstein, P. L., and Sims, P. F., 2001. Sampling error in eddy correlation flux measurements. Journal of Geophysical Research, 106: 3503-3509, doi: 10.1029/2000JD900731.

Fukai, S., Sittisuang, P., and Chanphengsay, M., 1998: Increasing production of rainfed lowland rice in drought prone environments. Plant Production Science, 1, 75-82, doi: 10.1626/pps.1.75.

Henderson - Sellers, A., Dickinson, R. E., Durbidge, T. B., Kennedy, P. J., McGuffie, K., \& Pitman, A. J., 1993: Tropical deforestation: Modeling local- to regional scale climate change. Journal of Geophysical Research, 98, 7289-7315. doi: 10.1029/92JD02830.

Kanae, S., Oki, T., and Musiake, K., 2001: Impact of deforestation on regional precipitation over the Ondpchina peninsula. Journal of Hydrometeorology. 2, 51-70. doi: 10.1175/15257541 (2001) 002<0051:IODORP > 2.0.CO;2.

Katata, G., Nagai, H., Ueda, H., Agam, N., and Berliner, P. R., 2007: Development of a land surface model including evaporation and adsorption processes in the soil for the land-air ex- 
change in arid regions. Journal of Hydrometeorology, 8, 1307 1325. doi: http://dx.doi.org/10.1175/2007JHM829.1

Kidron, G. J., 2000: Analysis of dew precipitation in three habitats within a small arid drainage basin, Negev Highlands, Israel. Atmospheric Research, 55, 257-270, doi: 10.1016/S01698095 (00) 00063-6.

Kim, W., Kanae, S., Agata Y., and Oki, T., 2005: Simulation of potential impacts of land use/cover changes on surface water fluxes in the Chaophraya river basin, Thailand. Journal of Geophysical Research, 110, D08110, doi: 10.1029/2004JD004825.

Kim, W., Komori, D., and Cho, J., 2009. The characteristic of relative error in eddy covariance measurements and its application to data quality control in rainfed paddy field. Journal of Agricultural Meteorology, 65, 201-207, doi: 10.2480/agrmet.65.2.11.

Kim, W., Cho, J., Komori, D., Aoki, M., Yokozawa, M., Kanae, S., and Oki, T., 2011. Tolerance of eddy covariance flux measurement. Hydrological Research Letters, 5: 73-77, doi: $10.3178 / \mathrm{hrl} .5 .73$.

Kim, W., Komori, D., Cho, J., Kanae S., and Oki T., 2014: Longterm analysis of evapotranspiration over a diverse land use area in northern Thailand. Hydrological Research Letters, 8, 45-40, doi: 10.3178/hrl.8.45.

Kim, W., Miyata, A., Ashraf, A., Maruyama, A., Chidthaisong, A. Jaikaeo, C., Komori, D., Ikoma, E., Sakurai, G., Seoh, H., Son, I., Cho, J., Kim J., Ono, K., Nusit, K., Moon, K., Mano, M., Yokozawa, M., Baten, M. A., Sanwangsri, M., Tida, M., Chaun, N., Polson, P., Yonemura, S., Kim, S., Miyazaki, S., Kanae S., Phonkasi, S., Kammales, S., Takimoto, T., Nakai, Ta., Iizumi, T., Surapipith, V., Sonklin, W., Lee, Y., Inoue, Y., Kim, Y., and Oki T., 2015: Fluxpro as a realtime monitoring and surveilling system for eddy covariance flux measurement. Journal of Agricultural Meteorology, 71, 32-50, doi: 10.2480/agrmet.D14-00034

Kosmas, C., N., G. Danalatos, J., Poesen, and B., van Wesemael, 1998: The effect of water vapour adsorption on soil moisture content under Mediterranean climatic conditions. Agricultural Water Management, 36, 157-168, doi: 10.1016/S03783774 (97) 00050-4.

Lee, T. S., Najim, M. M. M., and Aminul, M. H., 2004: Estimating evapotranspiration of irrigated rice at the West Coast of the Peninsular of Malaysia. Journal of Applied Irrigation Science, 39, 103-117.
Leuning, R., 2004: Measurements of trace gas fluxes in the atmosphere using eddy covariance: WPL corrections revisited. In Handbook of Micrometeorology (ed. by Lee X. et al.). Kluwer Academic Publishers, Netherlands, 119-132.

Meyers, T. P., Finkelstein, P., Clarke, J., Ellestad, T. G., and Sims, P. F., 1998: A multilayer model for inferring dry deposition using standard meteorological measurements. Journal of Geophysical Research, 103, 22645-22661.

Mutert, E, and Fairhurst, T. H., 2002: Developments in rice production in Southeast Asia. Better Crops International, 16, 1217.

Grunberger, O., Machaigne, P., Michelot, J., Hartmann, C., and Sukchan, S., 2008: Salt crust development in paddy fields owing to soil evaporation and drainage: Contribution of chloride and deuterium profile analysis. Journal of Hydrology, 348, 110-123, doi: 10.1016/j.hydrol.2007.09.039.

Panin, G. N., Tetzlaff, G., Raabe, A., 1998: Inhomogeneity of the land surface and problems in the parameterization of surface fluxes in natural conditions. Theoretical and Applied Climatology, 60, 163-178.

Redfern, S. K., Azzul, N., and Binamira, J. S., 2012: Rice in Southeast Asia: facing risks and vulnerabilities to respond to climate change. Building resilience for adaptation to climate change in the agriculture sector, 23, 295-314.

Tsubo, M., Fukai, S., Tuong, T. P., and Ouk, M., 2007: A water balance model for rainfed lowland rice fields emphasising lateral water movement within a toposequence. Ecological Modelling, 204, 503-515, doi: 10.1016/j.ecolmodel.2007.02.001.

Vickers, D., and Mahrt, L., 1997: Quality control and flux sampling problems for tower and aircraft data. Journal of Atomospheric and Oceanic Technology, 14, 512-526.

Wade, L. J., Fukai, S., Samson, B. K., Ali, A., and Mazid, M. A., 1999: Rainfed lowland rice: physical environment and cultivar requirements. Field Crops Research, 64, 3-12, doi: 10.1016/S0378-4290 (99) 00047-7.

Webb, E. K., Pearman, G. I., and Leuning, R., 1980: Correction of flux measurements for density effects due to heat and water vapor transfer, Quartely Journal of the Royal Meteorological Society, 106, 85-100.

Zheng, X., and Eltahir, E. A. B., 1998: The role of vegetation in the dynamics of west African monsoon. Journal of Climate, 11, 2078-2096. 